\title{
Measurement of antibiotic consumption in surgical ward of a tertiary care hospital
}

\author{
Rashmi R. Pujari' ${ }^{1}$ Bhabagrahi Rath ${ }^{1}$, Tapan Kumar Nayak ${ }^{2 *}$
}

\begin{abstract}
${ }^{1}$ Department of Pharmacology, ${ }^{2}$ Department of Surgery, Veer Surendra Sai Institute of Medical Science and Research, Burla, Sambalpur, Odisha, India
\end{abstract}

Received: 02 August 2020

Accepted: 05 September 2020

\author{
*Correspondence: \\ Dr. Tapan Kumar Nayak, \\ Email: rashmipujari13@gmail.com
}

Copyright: (C) the author(s), publisher and licensee Medip Academy. This is an open-access article distributed under the terms of the Creative Commons Attribution Non-Commercial License, which permits unrestricted non-commercial use, distribution, and reproduction in any medium, provided the original work is properly cited.

\begin{abstract}
Background: Antibiotic resistance is a global health problem. Improper use of antibiotics leads to development of antibiotic resistance, side effects, superinfections and increase in treatment costs. There are few publications on antibiotic consumption. Serious morbidity and mortality are associated with postoperative wound infections. The use of peri or pre-operative antibiotics has resulted in a reduced risk of postoperative infection when appropriate principles of prophylaxis are applied.

Methods: An observational study during a 2-month period was carried out in the department of surgery of Veer Surendra Sai Institute of Medical Science and Research, Burla. We utilized the administrative data for expression of antibiotic consumption using anatomical therapeutic classification (ATC) / defined daily dose (DDDs) methodology. The information included were drug names, strength, pharmaceutical form, quantity dispensed, total number of patients admitted during the study period and average length of stay. Each drug was then given a code according to the ATC classification. The number of DDDs and DDDs/100 bed days was calculated.

Results: The most frequent antibiotic used was cephalosporin group with DDDs 62.70 DDDs/100 bed days (44.34\%) followed by metronidazole with $23.10 \mathrm{DDDs} / 100$ bed days (16.34\%). Among cephalosporin group most common antibiotic used was ceftriaxone with 24.46 DDDs/100 bed days. The mean duration of stay was 7.2 days.

Conclusions: The results of this study are similar to previous studies and it showed that there is irrational use of antibiotics as there is no antibiotic policy in our hospital. Drug utilization research should be carried out at frequent intervals to improve rational use of antibiotics.
\end{abstract}

Keywords: Antibiotic resistance, Anatomical therapeutic classification, Defined daily dose, Bed day

\section{INTRODUCTION}

Anti-infective agents are the most frequently used group of drugs in our country. ${ }^{1}$ Unnecessary use of antibiotics has led to increased resistance, side effects, treatment costs. $^{2}$

Use of peri-operative antibiotics is an essential component in virtually all surgical procedures. ${ }^{3}$ There is no sufficient data on antibiotic use in our country. ${ }^{4}$ For the proper use of antibiotics, there is urgent need for vigillant surveillance, stringent infection control, rational antibiotic prescription. ${ }^{5}$

\section{Drug utilization research}

The marketing, distribution, prescription and use of drugs in a society, with special emphasis on resulting medical, social and economic consequences. ${ }^{6}$ It is carried out to achieve cost-effective health care and it forms the basis for making amendments in drug policies and helps in rational drug use. Antibiotic utilization studies help in 
improvement of appropriate and effective use of antibiotics.

\section{METHODS}

The design of this observational study was 2 months ( $1^{\text {st }}$ July 2019 to $30^{\text {th }}$ August 2019) Patients admitted to Department of General Surgery, VIMSAR, Burla.

\section{Inclusion criteria}

Records of all patients admitted to Dept of General Surgery

\section{Study procedure}

After obtaining permission from Institutional Ethics Committee (IEC), VIMSAR Burla, data were collected from drug administration and admission discharge records.

\section{Study tool}

(Anatomical therapeutic classification/Defined daily dose (ATC/DDD) methodology. ${ }^{7}$ Each antibiotic has an ATC code and DDD developed by WHO. The no. of DDDs, DDDs/100 bed days (ACI) and PDD (prescribed daily dose) were calculated.

DDD - the assumed average maintenance dose per day for a drug used for its main indication in adults. ${ }^{7}$

No. of DDDs $=($ No. of units administered in a given period $\times$ Strength)/DDD

ACI (Antibiotic consumption index) (DDDs/100 bed days $)=$ DDDs/no. of bed-days $\times 100$
No. of bed days $=$ No. of admissions $\times$ Average length of stay

Prescribed daily dose (PDD) of individual antibiotic were calculated and compared to its DDD.

\section{Statistical analysis}

All the data obtained were entered into Microsoft excel and analysed. Data were expressed in number and percentage.

\section{RESULTS}

Among the different antibiotics used in surgery ward, Cephalosporin group is the most commonly used group of antibiotics with 62.7 DDDs/100 BD (48.41\%) followed by Nitroimidazoles (18.24\%) followed by Amino glycosides $(9.1 \%)$ (Table 1) (Figure 1). Percentage of Total no. of DDDs represent in (Figure 2).

Table 1: DDDs/100 BD of different Antibiotic classes.

\begin{tabular}{|llll|}
\hline Antibiotic class & $\begin{array}{l}\text { No. of } \\
\text { DDDs }\end{array}$ & $\begin{array}{l}\text { DDDs/100 } \\
\text { bed days }\end{array}$ & $\%$ \\
\hline Cephalosporin & 6400 & 62.70 & 48.41 \\
\hline Nitroimidazoles & 2414 & 23.65 & 18.24 \\
\hline Aminoglycosides & 1210 & 11.85 & 9.1 \\
\hline Linezolid & 950 & 9.31 & 7.1 \\
\hline Penicillin & 846 & 8.29 & 6.4 \\
\hline Fluoroquinolones & 837 & 8.20 & 6.3 \\
\hline Carbapenem & 375 & 3.67 & 2.83 \\
\hline Macrolides & 182 & 1.78 & 1.3 \\
\hline Glycopeptides & 5 & 0.05 & 0.03 \\
\hline Total & 13219 & 129.5 & 100 \\
\hline
\end{tabular}

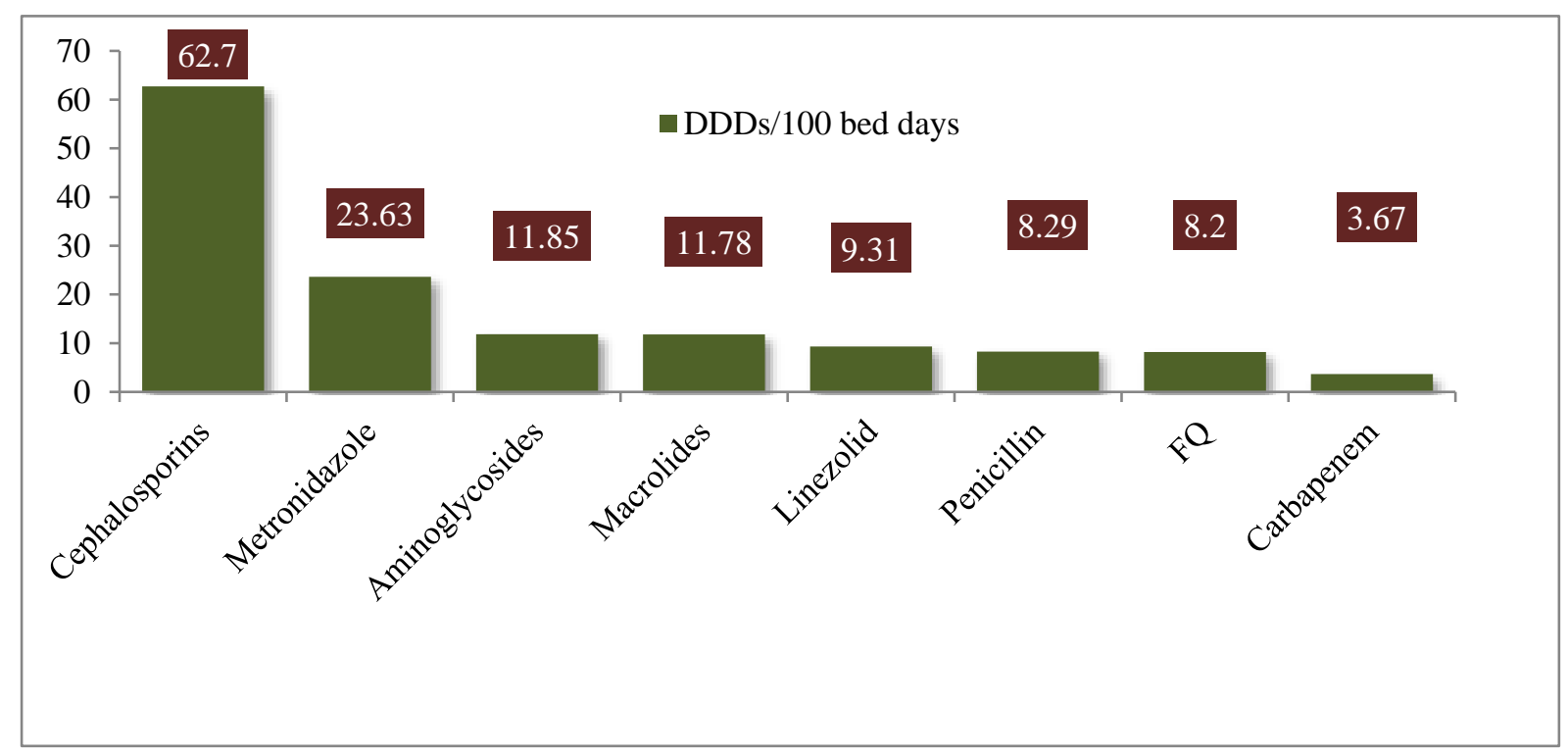

Figure 1: DDDs/100 bed days. 


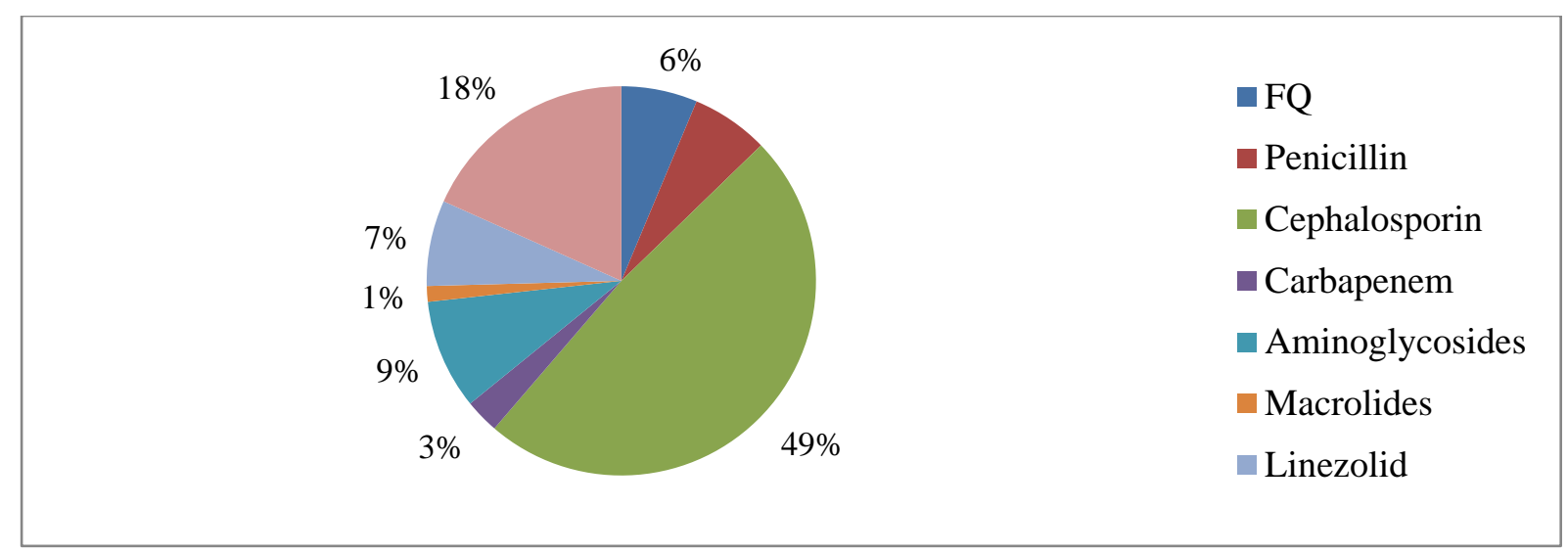

Figure 2: Percentage of Total no. of DDDs.

Injectable antibiotics $(61.83 \%)$ are commonly preferred over oral antibiotics (38.17\%) in the Dept of General surgery (Figure 3).

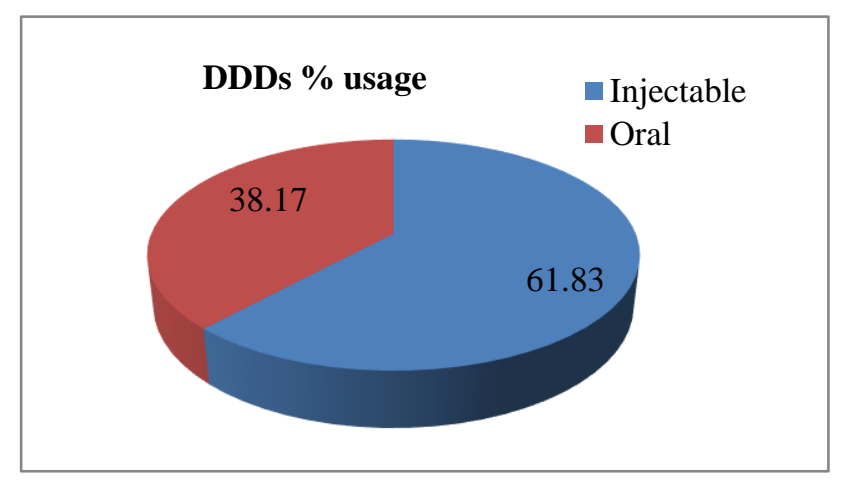

Figure 3: DDDs \% usage.

Among the cephalosporin group of antibiotics, ceftri axone is the most common antibiotic used with 26.46 DDDs/100 BD (42.2\%) followed by cefpodoxime (22\%) followed by cefixime $(17.57 \%$ ) (Table 2$)$.

Table 2: DDDs/100 BD of Cephalosporins.

\begin{tabular}{|llll|}
\hline Cephalosporins & DDDs & $\begin{array}{l}\text { DDDs/100 } \\
\text { bed days }\end{array}$ & \%age \\
\hline Ceftriaxone & 2700 & 26.46 & 42.2 \\
\hline Cefpodoxime & 1414 & 13.85 & 22 \\
\hline Cefixime & 1125 & 11.02 & 17.57 \\
\hline Cefoperazone & 1031 & 10.1 & 16.1 \\
\hline Cefadroxil & 118 & 1.15 & 1.8 \\
\hline Cefepime & 10 & 0.10 & 0.15 \\
\hline Cefotaxime & 3 & 0.02 & 0.03 \\
\hline
\end{tabular}

In my study, ceftriaxone has has higher PDD than DDD indicating that it is used at higher than normal doses. In other cephalosporins, PDD is lower than or same as DDD (Figure 4).

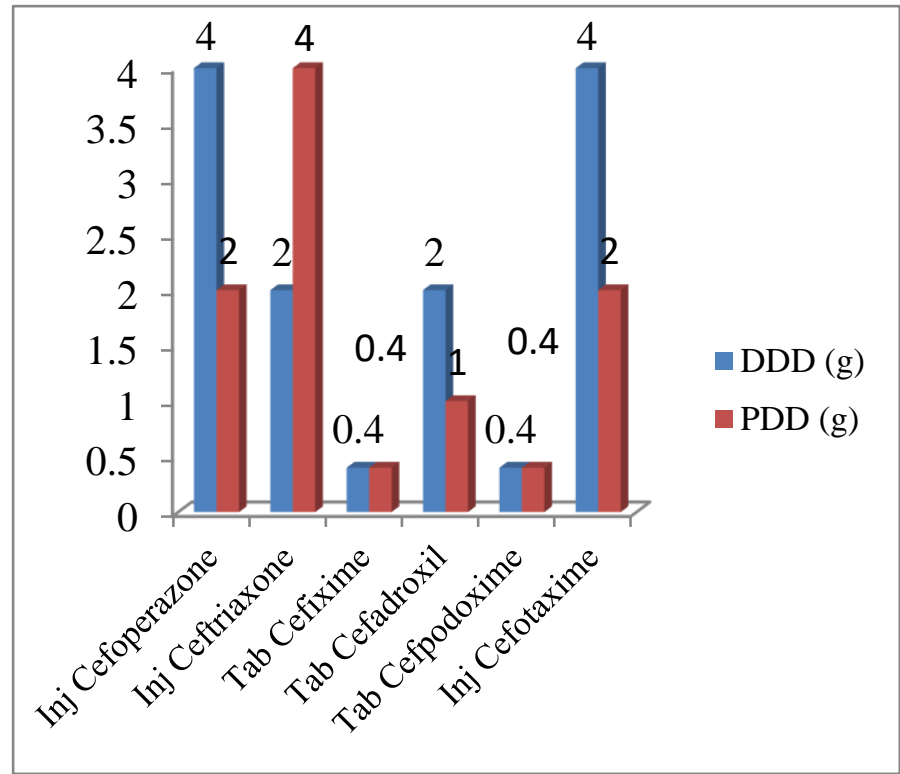

Figure 4: PDD Vs DDD of Cephalosporins.

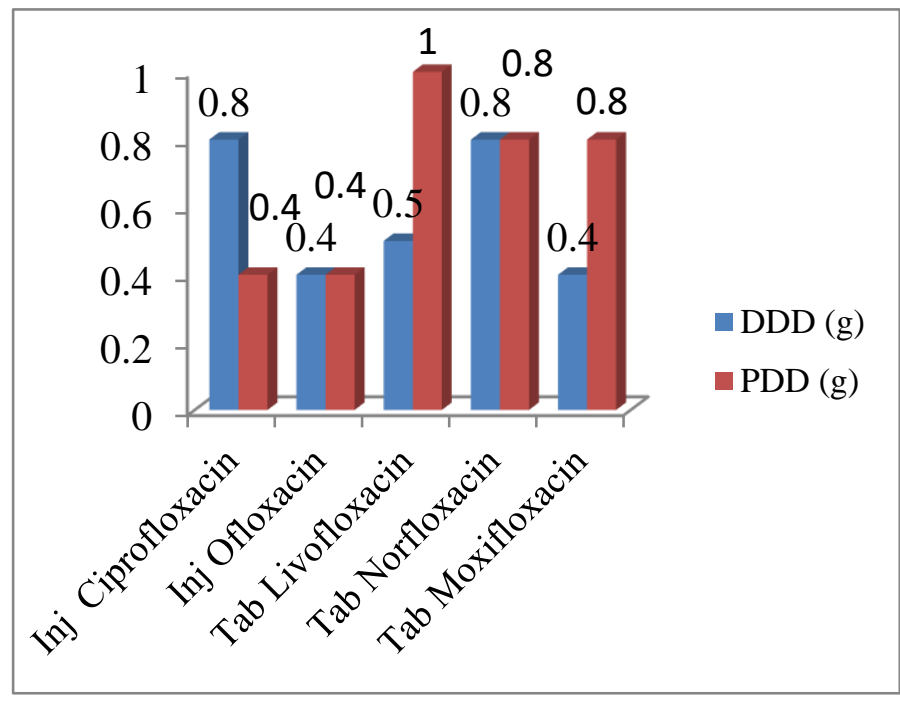

Figure 5: PDD Vs DDD of FQs. 


\section{DISCUSSION}

In our study, most frequently prescribed antibiotic Cephalosporin group with ACI of 62.70 DDDs/100 BD (48.41\%) followed by Metronidazole with ACI of 23.65 (18.24\%) followed by aminoglycosides with ACI of 11.85 $(9.1 \%)$ Sozen et al reported Cephalosporins constitute $57 \%$ followed by FQs with $14.70 \% .^{8}$

Among cephalosporin group, ceftriaxone constitute $42.2 \%$ (ACI of 24.46) followed by cefpodoxime with $22 \%$ (ACI of 13.85)- Aparna Williams et al 2019- the most frequently prescribed antibiotics were $3 \mathrm{rd}$ generation cephalosporins (ACI of 18.48) followed by metronidazole (ACI of 14.65). ${ }^{9}$

In contrary to this, a study done by Pesic et al cotrimoxazole was the most utilized antibiotic with 204.35 DDD/100 BD or $77.54 \%$ in Nis and 129.03 DDD/100 BD or $57.39 \%$ in Novi Sad. ${ }^{10}$ In another Indian study, the most commonly prescribed antibiotics at admission were cefaperazone/sulbactum or piperacillin/ tazobactam. ${ }^{11}$

\section{CONCLUSION}

In this study, Cephalosporin group is the most frequently used antibiotic in surgical wards. Amongst Cephalosporins, Ceftriaxone (3rd Gen.) is most commonly used. In comparision to Oral, Injectable antibiotics are more preferred. In our study- PDD of most of the antibiotics were found to be less than DDD. The average length of stay of patients is 7 days.

\section{ACKNOWLEDGEMENTS}

We would like to thank to the department of Pharmacology and the Department of Surgery for their timely support and cooperation.

Funding: No funding sources Conflict of interest: None declared

Ethical approval: The study was approved by the Institutional Ethics Committee

\section{REFERENCES}

1. Arda B, Yamazhan T, Sipahi OR, Taşbakan MI, Büke Ç, Ulusoy S. This is a very good idea for the Ege University Faculty of Health Sciences to provide you with the best practice possible. Hastane Infection Dergisi. 2004,8:14-5.

2. Cizman M: The use and resistance to antibiotics in the community. Int $\mathrm{J}$ Antimicrob Agents. 2003,21:297-307.

3. Haley RW, Schaberg DR, Crossley KB, Von Allmen $\mathrm{SD}$, McGowan JE Jr. Extra charges and prolongation of stay attributable to nosocomial infections: a prospective inter hospital comparison. Am J Med. 1981;70:51-8.

4. Hosoglu S, Esen S, Ozturk R: The effect of a restriction policy on the antimicrobial consumption in Turkey: a country-wide study. Eur J Clin Pharmacol. 2005,61:727-31.

5. Esposito S, Leone S. Antimicrobial treatment for intensive care unit (ICU) infections including the role of the infectious diseases specialist. Int J Antimicrob Agents. 2007;29:494-500.

6. Shankar PR, Upadhyay DK, Subish P, Bhandari RB, Das B. Drug utilisation among older inpatients in a teaching hospital in Western Nepal. Singapore Med J. 2010;51:28-34.

7. World Health Organization (WHO), Collaborating Centre for Drug Statistics Methodology: Guidelines for ATC classification and DDD assignment 2010. 2009, Available at, http://www.whocc.no/atcddd/. Accessed on 14 June 2019.

8. Sozen. Application of ATC/DDD methodology to evaluate antibiotic use in a general hospital of Turkey. Annals Clin Microbiology Anti-microbials. 2013;12:13.

9. Williams A, Mathai AS, Phillips AS. Antibiotic prescription audit in the intensive care unit. J Pharma Bioalli Sci. 2011;3:4.

10. Gordana Pesic. Application of ATC/DDD methodology to compare antibiotic utilization in two university hospital surgical departments. Med Biology. 2005;12(3):174-8.

11. Shrikala B, Kranthi K, Nafisa. A prospective study on evaluation of antibiotic prescription practices in an intensive care unit of a tertiary care hospital. J Clin Diag Res. 2010;4:3387-91.

Cite this article as: Pujari RR, Rath B, Nayak T. Measurement of antibiotic consumption in surgical ward of a tertiary care hospital. Int J Basic Clin Pharmacol. 2020;9:1565-8. 